\title{
Can Education Values Be Borrowed? Looking into Cultural Differences
}

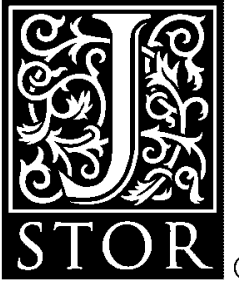

\author{
Kai-ming Cheng \\ Peabody Journal of Education, Vol. 73, No. 2, Leading Schools in a Global Era: A Cultural \\ Perspective. (1998), pp. 11-30.
}

Stable URL:

http://links.jstor.org/sici?sici=0161-956X\%281998\%2973\%3A2\%3C11\%3ACEVBBL\%3E2.0.CO\%3B2-K

Peabody Journal of Education is currently published by Lawrence Erlbaum Associates, Inc..

Your use of the JSTOR archive indicates your acceptance of JSTOR's Terms and Conditions of Use, available at http://www.jstor.org/about/terms.html. JSTOR's Terms and Conditions of Use provides, in part, that unless you have obtained prior permission, you may not download an entire issue of a journal or multiple copies of articles, and you may use content in the JSTOR archive only for your personal, non-commercial use.

Please contact the publisher regarding any further use of this work. Publisher contact information may be obtained at http://www.jstor.org/journals/leb.html.

Each copy of any part of a JSTOR transmission must contain the same copyright notice that appears on the screen or printed page of such transmission.

JSTOR is an independent not-for-profit organization dedicated to and preserving a digital archive of scholarly journals. For more information regarding JSTOR, please contact support@jstor.org. 


\section{Can Education Values Be Borrowed? Looking Into Cultural Differences}

Kai-ming Cheng

In this article I describe the cultural origins of educational values and practices in East Asia, particularly Japan and China. Values and assumptions concerning ability and effort have deeply rooted origins in the cultural traditions of these nations. The observable differences in educational practice and thinking between these nations and the West exist for reasons that lie beneath the surface. Such unseen factors are not easily changed by simple advocacy or even by formal educational policies. I argue that at the same time that trends toward global diffusion of educational policies are gathering steam, care must be taken to understand the cultural context from which policies are being borrowed and into which they will be implemented.

Elsewhere, I have argued that there is a cultural dimension that strongly affects thinking about and practice in education. I have illustrated the issue by discussing the cultural dimension in East Asian education and comparing that with education in mainstream Western societies (Cheng, 1990, 1994, 1995, 1997; Cheng \& Wong, 1996). In this article, I address the issue of societal culture, but from a policy perspective.

KAI-MING CHENG is Professor, Chair of Education, and Pro-Vice-Chancellor at the University of Hong Kong. He is currently also Visiting Professor of Education at the Harvard Graduate School of Education.

Requests for reprints should be sent to Kai-ming Cheng, Professor and Chair of Education, Pro-Vice-Chancellor, University of Hong Kong, Pokfulam, Hong Kong. E-mail: hradckm@hkucc.hku.hk 


\section{K. M. Cheng}

Education policies represent interventions into schooling practice. They are also manifestations of our ideas about education. It is interesting and potentially useful to discern the interplay between educational policy interventions and the cultural values of the society. In the context of rapid globalization, few educational policies in any country can evade external influences. At the same time, however, policy interventions borrowed from abroad may possess varying levels of compatibility with the cultural underpinnings of a given society.

Thus, it is legitimate to ask:

- To what extent do the cultural traditions of a society affect the implementation of policies for the improvement of education?

- To what extent could policies themselves alter the cultural values of a society about education?

These questions set the focus for inquiry in this article. More specifically, I discuss and contrast characteristics of East Asian education with those of the United States and other Western nations. This discussion forms the basis for an analysis of how well educational policies travel as they move from one cultural context to another.

\section{"The Learning Gap"}

In this section, I recapitulate some of the prevalent discussions in the literature related to the cultural dimensions of education. In so doing, I use illustrations from East Asia. The most widely read book about culture and education is perhaps Stevenson and Stigler's The Learning Gap (1992). This volume, which compared education in East Asia and the United States, was a bestseller in the United States immediately after its publication and is still widely discussed today. In it, the authors explored differences in predominant societal educational practices to account for differences in learning outcomes.

The argument presented by Stevenson and Stigler (1992) hinged on the dichotomy between effort and ability. They drew on research data collected over the course of a decade to demonstrate the existence of marked differences in the emphases given to education between parents in the United States and those in Japan and China. They concluded that parents in the United States attribute their children's success and failure to innate ability. In contrast, Japanese and Chinese parents appeared to pay greater attention to the effort of children and to the environment in which they learn: 
We and others have found that American children, teachers, and parents emphasize innate abilities as a component of success more strongly than their Chinese and Japanese counterparts do. ... Chinese and Japanese societies allow no excuses for lack of progress in school; regardless of one's current level of performance, opportunities for advancement are always believed to be available through more effort. High scores on a test are interpreted as a sign of diligence. (p. 95)

This is just one of many similar findings that Stevenson and Stigler (1992) reported and is essential to the thesis presented in this article. The reported belief in the positive effects of hard work is not an abstract credo, but a practical guide in the everyday lives of contemporary Chinese and Japanese. Hence, it is a matter of student, parent, and teacher beliefs that affect their daily practice without their thinking about it. In other words, these assumed beliefs and subsequent patterns of behavior are a matter of societal culture. Although Stevenson and Stigler did not use culture as an organizing concept in their book, they are indeed engaged in a discussion of culture and its effects on learning.

When writers look at culture, they use constructs such as artifacts, ceremonies, rituals, heroes, behavioral norms, shared values, and basic assumptions (see, e.g., Hofstede, 1991; Hoy \& Miskel, 1996; Schein, 1992). Assumptions about the interplay between effort and ability underlie a society's values with respect to education. For example, these assumptions shape perceptions about interstudent competition, levels of expectations conveyed to students, and norms concerning desirable behavior in schools. Expectations are communicated in the routines teachers use to handle learning difficulties and in the reinforcements they use to honor work. Stevenson and Stigler (1992) concluded that cultural variations in such beliefs ultimately explain differences in the organization of schooling and in the practice of learning in East Asian cultures. In a nutshell, what they discovered is an aspect of cultural difference between East Asian and American societies.

The cultural differences highlighted by Stevenson and Stigler (1992) echo observations, often implicit, in other writing about education in East Asia (e.g., Gardner, 1989; Lynn, 1988; White, 1987). Stevenson and Stigler made a significant contribution to the literature by succinctly delineating differences that might otherwise go unnoticed. Moreover, they were able to explain such differences in light of research data that hold little ambiguity.

At the same time, note that Stevenson and Stigler's (1992) recommendations about learning from the culture of Japanese and Chinese education found a lukewarm reception among American readers. Such a discomfort 


\section{K. M. Cheng}

is perhaps understandable, because identification of cultural differences often leads into the subject of values and value judgments. Anthropologists, whose role is to study culture, would regard value judgment as almost against their professional ethics.

Yet the consideration of educational practices used in other cultures brings with it implicit value judgments. It is difficult to avoid regarding some practices as "better" than others. Indeed, some assumptions-in this case, the relative emphasis given to ability and effort-are deemed more valid than others. In other words, borrowing educational practices from another culture may bring with it implicit cultural values. Examination of how we borrow or learn from another system goes beyond cultural analysis and moves into the arena of policy analysis.

Note that this conclusion goes beyond Stevenson and Stigler's (1992) original intention. They never intended to conduct a cultural analysis per se. Their academic inquiry focused on differences in basic assumptions held about the learning of children across several societies. The differences they discovered have deep roots in the cultural norms, values, and assumptions of the particular societies. These cultural roots go well beyond school education.

Education is a social-cultural process. The process of borrowing educational practices from another society implies an acceptance of cultural values embedded in the particular practices (e.g., time in school, role of tests, discipline policies, instructional methods). This suggests the possibility that implementation of foreign educational policies and practices could result in a subsequent shift in the value system of a society. The receiving society may not, however, be prepared (or able) to undertake such a fundamental change despite the desired change in policy outcomes, such as student achievement.

In the following section, I further develop this argument and explore cultural explanations underlying the learning gap. I discuss this from three perspectives and demonstrate how differences observed across societies in educational practices could reflect differences in deeply rooted cultural values.

\section{The First Dimension: Individualism Versus Collectivism}

There is a growing body of literature that discusses cultural values on the individualism-collectivism continuum. Central to this analysis is attention paid to the concept of self, a recurring focus of exploration in cultural studies. How people conceive of self varies widely among Eastern and Western cultures. 
Hsu $(1971,1985)$ observed that the concept of self in the Western sense of the term was virtually absent in the Chinese culture. The term wo ( $I$ or self in Chinese) has always been used exclusively in a social context. As such, it is in essence a relative concept. Chinese people assume that the smaller self (xiaowo) should always submit to the larger self (dawo). Here the smaller self may refer to individuals, families, and so forth depending on the context. Thus, individuals are expected to submit themselves to collectives; a smaller collective is expected to submit itself to the larger collective.

This echoes what Fei (1947/1985) observed: Chinese societies are organized into a configuration of hierarchy, where individuals exist only as members of a community. It is only through membership and by having a defined position in the social hierarchy that the individual gains an identity. Fei contrasted this with Western society, which he referred to as a configuration of association. Here individuals associate with one another as an ad hoc necessity due to particular needs. They carry their identity with them as a feature of personality rather than social hierarchy.

These observations are more rigorously supported by Hofstede's empirical study (1980) of the characteristics of different cultures. In his now classic study of more than 117,000 IBM employees from 66 countries, Hofstede identified consistent patterns of difference attributable to national culture. Interestingly, he noted three "outliers" that stood out as "significantly less individualistic than their wealth would warrant" (p. 231). In these countries-Singapore, Hong Kong, and Taiwan-cultural similarities to mainstream Chinese culture appeared stronger than the influences of global socioeconomic development.

Hofstede used data on cultural differences on the dimension of individualism-collectivism to explain various social phenomena in Chinese societies. He cited Mao Zedong's extreme ideology of anti-individualism as one example. He noted the prevalent role played by face in Chinese societies. Face refers to the status expectations held by an individual as a result of his or her group-associated identity. For an individual to lose face means to "fail to meet essential requirements placed upon him by virtue of the social position he occupies" (Ho, 1976, p. 867). One may also find elaborate discussions of the issue elsewhere (Kim, Triandis, Kagitchibasi, Choi, \& Yoon, 1994).

Individualism-collectivism in education. In the collectivist cultures of East Asia, education is viewed first and foremost as a means of socialization. It is an organized means by which children learn to adapt themselves to the expectations of the larger community. School education is designed to instill in children the norms and expectations of the society. 


\section{K. M. Cheng}

This framework illuminates the extraordinary significance that extrinsic motivation plays in student learning in Asian societies (Biggs, 1996; Lynn, 1988). The strong weight accorded to the group helps to explain the uniformity and conformity that characterize East Asian educational systems. The cultural priority of clearly delineating one's status within the collective leads naturally to an educational system that emphasizes examinations and competition. Finally, these characteristics suggest why effort is valued over ability.

In contrast, cultures where individualism dominates, such as in many Western nations, tend to view education as a means of empowering children. The goal is to enable children to grow and respect themselves as individuals. Schools and parents encourage children to develop according to their unique needs and potentialities. Consequently, education systems tend to honor individuality over conformity and individual ability over effort.

Cultural norms such as these are also revealed in the legal framework of education. For example, in nations such as the United States there is a formally enshrined expectation that the system will adapt to the needs of individuals. This is evident in diverse areas. For example, in special education individual educational plans are drawn up for every student. With respect to student discipline, due process rights of the individual take precedence over the substance of student behavior in the classroom.

This also begins to explain the diversity in system structures that have evolved in education systems of the West. This contrasts again with Asia where standardization of every thing from school architecture to curriculum is viewed quite positively. In European nations such as Germany, France, and the Netherlands, schools cater to students with different aptitudes and interests. In the United States, students are given diverse choices among curricula within the same school system and sometimes within a single school. In cultural contexts that place a high value on individualism, the education system seeks to maximize adaptation to individual needs as far as resources permit.

As just suggested, the cultural consequences of individualism-collectivism also carry over into the relative emphasis that parents and teachers place on ability and effort. The emphasis on effort and hard work in education in Chinese societies is attributable, to at least some extent, to the collectivist culture. For more than 2,000 years since the time of Confucius, examinations were the means of selection or nomination for high-status positions within officialdom. In the 1,000 years between the Sung dynasty until the downfall of the monarchy in 1911, civil examinations were an important annual national exercise. The civil examination, and nothing else, was the social ladder that enabled upward mobility. As Schirokauer (1976) 
observed, in the Chinese system the civil service examinations stood alone as the route to success.

Over the course of many dynasties, individuals who aspired to higher positions in the hierarchy had to submit themselves to the national examination. For centuries, they all studied the same Four Books and Five Classics. All aspirants had to learn the required format of essay writing for the civil examination (see Miyazaki, 1963/1976, for detailed descriptions). There was only one single track by which one could move upwards.

It is notable that by tradition learning was synonymous with "reading the books" $(d u s h u)$. The aim of "education" was "understanding the selected books and knowing the rituals" (zhishu shili). The acquisition of knowledge and skills as an objective of education is only a recent development. It emerged when the modern school system came into being at the turn of the 20th century. Most of the time, "reading the books" could mean simplistic memorization, or "rote learning," as Western observers would label it.

The uniformity and simplicity in the desired mode of study was a sign of "fair competition." It was applicable to all individuals regardless of their background and abilities. It was a means of increasing the likelihood that effort and hard work would be rewarded in the learning game. ${ }^{1}$ The ultimate reward-the top prize-for the champion was remarkable: appointment to a ministerial position and marriage to a princess.

Although the civil examination has gone forever, its spirit remains firmly embedded in China's modern education system. In fact, in mainland China formal education remains the only path for conversion of rural citizenship into urban citizenship. In Japan, passing the university entrance examination is still a necessary first step toward a respectable career. Thus, children labor under incredible pressure to study for and pass their exams. To a significant degree education is still seen as the major, though no longer the only, route for upward mobility in East Asian societies.

When viewed from this perspective it becomes easy to see how learning is strongly related to social expectations. In Chinese and Japanese societies, student motivation is linked directly to external factors (Biggs, 1996; Lynn, 1988). This was reflected in Stevenson and Stigler's (1992) observations:

Group identification provides a strong, effective means of heightening children's motivation toward particular goals. ... This does not mean that individual accomplishment is disparaged; rather, it becomes something that enhances the prestige of the child's group or family. ... The

\footnotetext{
${ }^{1} \mathrm{I}$ am inspired in this argument by Naoko Iwasaka, who made an excellent presentation on the topic in my class at Harvard Graduate School of Education in the spring of 1997.
} 
power of the group is also used as a means of motivating children. (pp. 89-90)

Under these circumstances, the implications are double edged. On the one hand, there is still the traditional cultural press toward uniformity and conformity. Individuals are under enormous social pressure to adapt themselves to the system. This explains in part the weakness in creativity that has recently been highlighted among Asian economies.

On the other hand, East Asian educational systems tend to downplay the role of innate ability. They emphasize the positive consequences of hard work. It is expected that, barring some biological problem, all students can achieve. In contrast with some Western nations, for example, Chinese teachers do not need to be convinced that all children can learn. This is a social-cultural expectation, a normative belief that pervades the culture and its schools. This explains the "learning gap" and in part the East Asian economic miracle.

\section{The Second Dimension: Physical World Versus the Social World}

Gardner (1984) considered three different realms "that must necessarily be confronted in every corner of the world" (p. 260):

1. The physical world, the world of natural objects and the elements as well as various forms of living matter.

2. The world of manmade artifacts, such as tools and works of art, as well as the less tangible world of words and ideas.

3. The social world, which includes other persons, those in the family, in the community, and, increasingly, in the rest of the world as well.

He further classified cultures by looking at the ways in which they define these realms, the kind of knowledge that is captured in each realm, and the values that are placed on each realm. Gardner observed that some societies emphasize the physical world, whereas others emphasize the social world. He classified Western societies as an example of the former, and Japan and India as examples of the latter. According to this system of classification, Chinese societies also fall into the latter category.

Gardner (1984) further asserted that this system of classification has implications for education. Societies that emphasize the physical world give greater attention to the development of abstract knowledge as well as technical knowledge and skills. Societies that are more concerned with the social world emphasize the social and moral domain. 
For example, Western culture places a great deal of importance on explicit knowledge about the physical world, and indeed this knowledge is central to much of the educational system and its focus on the physical and natural sciences. ... In many other corners of the world, explicit knowledge, particularly as it is captured in scientific form, is of much less importance. ... However, at the same time, in such cultures as Japan and India, knowledge about the social world and how one negotiates one's way within it is valued much more and harnesses far more energy than does knowledge about the physical world. (Gardner, 1984, p. 261)

This point receives validation in the observations of many other East Asian scholars. Again, Stevenson and Stigler (1992) observed that among Japanese and Chinese parents, "much more importance is given to establishing interdependent relationships between the child and other members of the family and society" (p. 89). There have also been in-depth studies of how cultural norms carry over into educational settings.

Tobin, Wu, and Davison (1989), for example, used ethnographic approaches to explore differences in preschool education as practiced in Japan, China, and the United States. They found that Japanese preschool education emphasizes the class. Immersion in the child's class teaches how to lead a life within one's community. Indeed, in most East Asian systems of education, the class is an essential element of school education (see, e.g., descriptions by Stevenson \& Lee, 1997).

This emphasis on the collective has other interesting educational implications. For instance, in East Asian cultures, small class sizes are not always preferred.Small classes could limit or weaken opportunities for interactions with other students. The following conversation reported in Tobin et al.'s (1989) study is enlightening, if not surprising, to observers outside of Japan:

"So you think it would be better to have a class size of ten or twelve instead of twenty-five or thirty?"

"No, I won't say better. Well, maybe you could say it is better for the teacher, but not better for the children. Children need to have the experience of being in a large group in order to learn to relate to lots of kinds of children in lots of kinds of situations." (pp. 36-37)

This is quite a contrast with the concept of a class in Western school systems. There, the class size is more often than not a direct reflection of resource limitations. Small class size is always preferred by students, teachers, and parents. Only then can students receive the individual attention of the teacher needed to bring out the student's fullest potential. 


\section{K. M. Cheng}

As just suggested, the function of a class goes well beyond pedagogy. In Taiwan and on the Chinese mainland, throughout primary and secondary schools, the class is a formal organization with a structure of student self-government. Often there is a class association with a properly elected chairman and an executive committee. There are members in charge of academics, finances, recreation, sports, and welfare. In some cases, class associations are the grassroots units of the schoolwide student union (often called the "students' self-governing association" in China).

The class teacher (i.e., the "homeroom" teacher) has the heavy but conventional responsibility of supervising the class and looking after the personal development of each member of the class. Development of the students as social beings is viewed as important as knowledge acquisition, if not more so. In this light, the class is seen as an essential vehicle for socialization. For example, as observed in a large-scale study in China (Cheng, 1996):

The class teacher is therefore an organizer, a leader, a social worker, a counselor, a remedial teacher and, sometimes, a private tutor to the academically weak. In short, the class teacher is in charge of the comprehensive development of each student in his/her class. (pp. 114-115)

These duties of the class teacher represent but one aspect of a teacher's role beyond instruction. In what is perhaps equivalent to pastoral care in the West, teachers in China and Japan spend a large part of their time in the noninstructional realm. Many teachers in these systems have to act as supervisors of extracurricular clubs or teams. They pay home visits, help preside over school assemblies, and conduct many other activities that have little to do with direct classroom teaching. Contrast this with the United States, where regulations and union rules have defined the teacher's role almost exclusively as classroom instruction.

Discipline is another example. In many Western systems of education, discipline is viewed as a necessary evil that fosters orderly learning. Teachers tend to learn classroom management skills to prevent and solve behavior problems. School faculties learn to implement systems of schoolwide discipline (e.g., assertive discipline) when and only when there is a perception that school discipline is weak.

In East Asian systems of education, there is a conspicuous emphasis on discipline for its own sake. Discipline does not receive focus only for the pragmatic purpose of effective teaching and learning. Discipline is itself a primary objective of education. Teachers explicitly teach children how to learn to respect norms laid down by the community. School discipline is seen as a positive, necessary, and valued aspect of socialization. 
In this context, the notion of moral education as it is defined in China and Japan merits some discussion. In all Chinese communities, education comprises either three or five dimensions: moral, cognitive, and physical development; or moral, cognitive, physical, community, and aesthetic development. Note that the order represents the significance attached to each. The former system is used on the Chinese mainland; the latter is more common in Taiwan. In both cases, however, the moral dimension represents a top priority of education.

In Chinese societies, the content of moral education has varied over time. Nonetheless, it has always focused on the development of personal character and the instillation of a sense of commitment to the community. In contemporary mainland China, the aims of moral education in primary schools include the "five loves": "love the motherland, love the people, love science, love doing labor, and love socialism." It also includes "abilities to manage oneself, help others, serve the collective, and distinguish right from wrong" (Guidelines for Moral Education in Primary Schools, 1988; quoted in Y. J. Liu, 1993).

As White (1987) also observed in Japan, the distinction that Western societies make between "social" and "personal" morality is rarely made. A moral dilemma is almost always regarded as a social or interpersonal problem. That is, even personal development in the affective domain is conceived of within a social context, and is a matter of learning how to adapt to the society.

This contrasts with the aims of education in the West. In mainstream Western culture, knowledge and skills form the main content of education. Although there are discussions about moral education, values education, and affective education, these are (a) often peripheral when compared with education in the cognitive domain, (b) conceived as a matter of personal development rather than as a matter of transmission of social norms, or (c) often included as part of the knowledge domain (i.e., learning about morals).

To carry the argument further, one may even say that the social or moral dimension is the primary aim of Chinese and Japanese education. Cognitive knowledge is respected only when it serves the moral aim. Indeed, as strange as it may seem, the emphasis given to memorization of cognitive knowledge illustrates this point. The process of memorization is seen as a form of training, discipline, and hard work. The content that students memorize (let alone what is understood) is actually secondary. Sports and other extracurricular activities are similarly viewed as tools for training students in team spirit and commitment to the collective will. Direct concern for physical fitness or students' athletic interests is secondary. 
Attention to social relationships is a shared value in the educational community. In a multisite study of basic education carried out in China (Cheng, 1996), parents agreed that "poor adaptability" and "poor human relations" were the essential characteristics of those who could not survive in society. According to the parents,

adaptability includes adaptation to nature and changing environments, endurance and persistence, imagination and creativity, and self-study skills. Human relations include relations with family members, relations with peers and work-mates, and the management of oneself in an organization. (pp. 64-66)

In the same study, parents also placed high emphasis on "relations" as one of the major expectations of primary schooling (p. 61). This points to the conclusion that "moral conduct is seen as more important than intellectual abilities as objectives of basic education" (p. 65).

One also has to refer to the society at large to understand this shared emphasis on the social world. Relations, or guanxi as they are known in the literature of Chinese studies, have always been an integral facet in Chinese cultures. Relations here refer to a form of interpersonal networking. This type of networking contrasts with the often rigid hierarchical structures that are defined by law and regulations. Guanxi is a "distinct version of human order" with "clear and well-understood rules" developed among Chinese societies (Redding, 1990, p. 58).

In a positive sense, relations provide a form of lubricant to rigorous formalism, rationality, and legalism. In a negative sense, relations create an insider network that can result in unequal access or favoritism in resource allocation. This article does not purport to pass judgment on the role of relations in Chinese societies. However, it is essential to understand that collective human relationships play a much more significant role in East Asian societies than in the West.

Social relationships, and hence attention to the social world, therefore become an essential element in education. Social dimensions of education prepare the younger generation to lead a life in such societies. Discipline and the work ethic in East Asian societies are often seen as conducive to effective learning and academic excellence. They are not just results of a set of educational practices, however. They are part and parcel of a social culture that places a primary emphasis on social relationships. In such a culture, discipline and the work ethic are not conceived as a means toward learning, but as ends in themselves. 
The distinction between analytic and holistic methodology is by no means foreign to academic discourse. Indeed, in the realm of cultural studies, psychologists and anthropologists represent two distinct methodologies. Psychologists tend to discern culture through analysis of discrete variables. Hofstede's (1980) classic study, mentioned earlier, exemplifies the application of psychological methodology to the study of culture.

In contrast, anthropologists take a holistic or synthetic approach to the study of culture. They seek to make meaning from the whole of their experience in the field. They synthesize the sum of their descriptions of the culture they experience. I suggest that cultural differences may also play a role in the preferred methodological or perceptual approaches used within a culture.

T. Y. Liu (1988), from Australia, extrapolated his observations from the study of language to cultures in general. His research contrasted the analytic approach that dominates in the Western culture to the synthetic or holistic approach that characterizes East Asian societies. By way of example, he noted the synthetic use of Chinese linguistic characters with the discrete letters used in the Roman system. He also delineated a range of everyday cultural practices, such as the use of the "all-purpose chopsticks" or monolithic vessels for drinks and food in Chinese lives. T. Y. Liu concluded:

I would not hesitate to say that Westerners have ingrained in their culture and milieu a very strong analytic ability. As if created by the Almighty for a change, the Asians, and in particular the Chinese, seem to have a highly developed sense of synthesis. ... The Chinese ... have derived a kind of mellow wisdom from myriad elements and built them up into a unified whole. (p. 46)

He is not alone in making this observation. C. L. Liu (1990), from China, made an extensive study of Chinese theories about the universe, management, medical science, aesthetics, and ecology and agriculture. In this treatise, C. L. Liu made an important attempt to delineate the methodology or preferred "ways of seeing" used in ancient China and to contrast these with the methodology preferred in Western cultures. He equated what he referred to as Chinese "systems thinking" with "holistic thinking" (p. 6).

For example, C. L. Liu (1990) discerned that ancient Chinese philosophy, regardless of the diverse schools of thought, regards the universe as a comprehensive ecological system. In such a system, various parts are 


\section{K. M. Cheng}

interrelated and mutually influential. Such internal dynamics are the driving force of development of the system. The system itself evolves in cycles relying on self-feedback mechanisms. Such an ecological system includes human beings as an integral part.

C. L. Liu (1990) argued that, in the absence of sophisticated tools for analysis and technologies for experimentation, the ancient Chinese tended to avoid detailed analysis. Instead, they focused on the development of holistic explanations (i.e., theories), which were largely based on experience and intuitive observations. Such an approach, reinforced by success in human interaction with nature, developed into a consistent methodology or culturally dominant way of approaching the world.

The success of such a methodology is well illustrated in traditional Chinese medical theories. In the broad framework of yin-yang (which is better known to the West), traditional Chinese medical theory perceives the human body as a holistic system. The system embraces different dimensions of equilibrium. Each dimension can be understood as a continuum between contrasting states. Health is represented by equilibrium in all of these dimensions and illness occurs when the equilibrium is upset. Diagnosis is conducted through the detection of certain symptoms. Medical treatment is designed to stimulate or mobilize the body, as a holistic system, to make self-adjustments, and therefore to restore equilibrium (C. L. Liu, 1990).

Also pertinent to the discussion here is C. L. Liu's analysis of Confucianism. C. L. Liu (1990) interpreted Confucianism as a "theory of social management" (p. 204). Confucius adopted a holistic view of the world. He conceived an integrative relationship between the emperor, the officialdom, and the citizens. In so doing, Confucius attempted to create an ecological framework in which individuals, families, the state, and the world could harmoniously coexist. In this Confucian system, each person has a role to play, but all people are interdependent and mutually constrained.

People are central to the Confucian framework. Confucius believed that management of the individual self is the fundamental starting point of management of the entire society (C. L. Liu, 1990). Hence, he placed a heavy emphasis on self-cultivation of a "gentleman." This conception refers to a holistic and idealistic model of a human being. The gentleman is a wellrounded person with a perfect personality (i.e., morality), who is committed to making a positive contribution to the society. Education, as a socialization process, should foster citizens with these characteristics.

This holistic methodology has become embedded in Chinese education. In the West, aims and objectives of education are often realized as a list of categories of expected knowledge and skills to be learned by students. In East Asia, education is often regarded as the holistic process of bringing up 
all-around human beings. In the West, the ultimate aim of education is to develop fully the potential capacity of individuals. In East Asia, the ultimate aim of education is to cultivate a person so that he or she can and will contribute to the society.

Under this mode of holistic thinking, morality and knowledge are inseparable. In other words, there is no such thing as "knowledge for the sake of knowledge." All knowledge should be subject to scrutiny in terms of its social application.

Thus, the performance of a student is judged more by moral conduct than by knowledge and skills. Teachers are therefore seen primarily as holistic role models, rather than as transmitters of knowledge. Schools are seldom assessed through analytic means such as performance indicators. Schools are good when they have a good atmosphere (xiaofeng). This is a concept that is somewhere between school climate (which is more easily changed) and school culture (which is longer lasting).

\section{Implications for Education Policies}

In this article, I have sought to describe the cultural origins of educational values, norms, and practices that have been associated in recent years with East Asian societies, particularly Japan and China. Values and assumptions concerning the role of ability and effort in education of the young have deeply rooted origins in the cultural traditions of these nations. The learning gap is much wider than one can explain from practice on the surface. The observable differences in educational practice and thinking exist for reasons which lie beneath the surface deeply rooted in the social culture.

\section{Educational Policy and Societal Culture}

These cultural factors are difficult to change by simple advocacy or even via formal educational policies. They are longer lasting than the lifetime of any education policy and indeed any political regime. They grow out of the values and norms of a nation's culture.

I have asserted that the emphasis on effort in Japanese and Chinese societies is partly derived from the submission of individuals to the collective community. It is the case that the society will reward those who have worked hard, but in a way prescribed by the society. Moreover, the attribute of hard work is seen as a moral virtue. Within the culture, this virtue is viewed as more important than the substance of learning.

Such virtues fit the ultimate aim of East Asian educational systems: to cultivate all-around, ever-adaptive, holistic human beings who live accord- 


\section{K. M. Cheng}

ing to social norms and are committed to the community. Such an education does not favor those who do not conform to social expectations. This is true regardless of the innate ability and the knowledge they may possess.

If we again use the emphasis on effort as an example, I would not argue that such an emphasis is necessarily the product of a collective society. Hard work also typifies many individualistic societies. As Stevenson and Stigler (1992) rightly pointed out, Americans view themselves as rugged individualists who can accomplish whatever goals they set if they work hard enough. However, it is difficult to conceive that American parents would switch their focus or belief away from their child's innate ability overnight.

There are reasons why Chinese and Japanese parent favor such an emphasis. Moreover, these factors do not readily exist in American societies. Similar analysis might reveal that there are equally deeply rooted causes for American parents to emphasize individual ability. American cultural norms may also contribute to other aspects of American lives that are seen as successful.

Thus, what role would policy play in emulating Japanese or Chinese educational practices? There are perhaps two lessons here. First, from a policy perspective, educational policies will only succeed when they are consistent with the cultural values embedded in the larger social context. That is, if we admit that the effort-ability dichotomy is rooted in culture, then policies should be so designed to fit the culture. It is unlikely that the transfer of policies of China or Japan to the United States would be well suited to the beliefs and assumptions of Americans. Moreover, it is unlikely that those policies would have a strong impact on American beliefs, assumptions, and behaviors.

Cultures do change, but they change at a pace that is beyond the tolerance of any human policy system. In this context, one has to watch out for the limits of educational policies. Policies are likely to be effective only when they are consistent with the culture of a particular society and when they go along in the direction of ongoing cultural processes. It is rare that policies that run counter to the society's cultural norms will succeed in changing educational practice.

At this juncture, it might be useful to refer to Schein's (1992) working definition of culture:

a pattern of shared basic assumptions that the group learned as it solved its problems of external adaptation and internal integration, that has worked well enough to be considered valid and, therefore, to be taught to new members as the correct way to perceive, think, and feel in relation to those problems. (p. 12) 
If we believe that cultures develop alternative solutions to similar problems, then we should have faith in all cultures. We should believe that there are multiple ways of achieving effective learning in an individualistic society, which relies more heavily on analytic methodology and emphasizes knowledge and skills. This will not necessarily mean borrowing from a collectivist society that adopts holistic methodology and emphasizes social relationships.

There should be no implication from this argument that cross-cultural borrowing is always impossible or improper. With the increasing intensity of global exchange, cultures do learn from one another. There are certain aspects of human life that may witness some global convergence. However, I do not accept that the world will converge into one culture, as in the metaphor in which many diverse streams will "become one uniform stream" (Inkeles, 1997, p. 71).

For example, global convergence in some aspects is accompanied by more diversity than in others. The development in languages is illustrative of such a trend. In recent decades, there has been a convergence to some extent on the use of English as an international language. At the same time, there has been an increased emphasis on the use of indigenous languages (for more elaborate discussion, see McKay, 1992).

\section{The Challenge of Cultural Diversity}

More intensive global interactions have brought about more opportunities of cultural diversity in education. Immigrants in large numbers have turned most metropolitan cities into multicultural societies. More countries (e.g., Australia) follow the footpath of the United States and try to accommodate multiple cultures. Newly emerging states (e.g., in Eastern Europe and Central Asia) face the dilemma of developing their respective traditional cultures on the one hand and accepting Western values on the other.

For educators and school leaders in general, there is the imminent challenge of cultural diversity among students and hence their learning styles. There are nations such as the United States and Australia, where only a few classrooms are not multiethnic. Students from diverse family backgrounds carry with them diverse values and assumptions about education and learning. Such a diversity sustains, not only because there is a normative belief that diversity should be encouraged, but also because there is only a weak mainstream culture about education that could overcome the diversity. It is perhaps more realistic for educators to prepare for such a diversity. However, how can educators accommodate diverse learning cultures under one roof? The question is yet to be answered.

There are also places such as Hong Kong, where two major cultures meet or confront each other. On the one hand, the traditional values of a Confucian 


\section{K. M. Cheng}

society have contributed to its economic success; no less is education's contribution. On the other hand, the openness that is essential to the thriving economy has also brought with it values that prevail in the industrialized West.

The society benefits from both cultures, but only through a continuous resolution of cultural conflicts. How can the society at large, and educators in particular, reconcile the expected commitment of individuals to the social community with the increasing emphasis on individual values? How can the respect for competition, which has brought success to the society, come to terms with the care for individual needs? How can one maintain the splendid diversity that is essential to the vitality of the city, yet be able to secure the concerted views and plans that are necessary to bring the city forward? These are again questions to be answered.

There are also other societies, such as those in China and the former Soviet republics, where cultures that were never challenged within a closed system are now confronted by foreign values. Assumptions and practices in education, which had been in place for a long time, will be tested in the coming years. In a sense, they will need to be revalidated given the changing population of students in a changing world.

A short article such as this should not be expected to seek answers for such gross questions. The purpose of these questions is to alert educational policymakers and leaders that cultural diversity is inevitable in our education systems. We do not have to be postmodernists to appreciate the challenge of such diversity. As such, it is futile to aim at the identification of an ultimate model of educational values. It would be far more enlightening if the policy agenda that is spreading internationally is set to accommodate diversity in educational values and practices.

Practical solutions to multicultural challenges are identifiable only through a long journey of exploration and experiments. However, such a journey will succeed only if educators and policymakers keep a more open mind about the role and impact of culture on educational processes. In other words, if one admits that many education challenges are cultural in nature, the first step toward policy solutions should be an awareness of culture. It is our local values and assumptions that matter at the level of educational practice when we consider globally diffused educational policies. I refer back to the approach taken by anthropologists. Cultures are equally valid; no culture is superior to another.

\section{References}

Biggs, J. B. (1996). Western misperceptions of the Confucian-heritage learning culture. In D. A. Watkins \& J. B. Biggs (Eds.), The Chinese learner: Cultural, psychological and contextual influences (pp. 45-68). Hong Kong and Melbourne: Comparative Education Centre and the Australian Council for Educational Research. 
Cheng, K. M. (1990). The culture of schooling in East Asia. In N. Entwistle (Ed.), Handbook of educational ideas and practices (pp. 163-173). London: Routledge.

Cheng, K. M. (1994). Quality of education as perceived in the Chinese culture. In T. Takala (Ed.), Quality of education in the context of culture in developing countries (pp. 67-84). Tampere, Finland: Tampere University Press.

Cheng, K. M. (1995). The neglected dimension: Cultural comparison in educational administration. In K. C. Wong \& K. M. Cheng (Eds.), Educational leadership and change (pp. 87-102). Hong Kong: Hong Kong University Press.

Cheng, K. M. (1996). Quality of basic education in China: A case study of the province of Zhejiang. Paris: International Institute for Educational Planning.

Cheng, K. M. (1997). Quality assurance in education: The East Asian perspective. In K. Watson, S. Modgil, \& C. Modgil (Eds.), Educational dilemmas: Debate and diversity: Vol. 4. Quality in education (pp. 399-410). London: Cassell.

Cheng, K. M., \& Wong, K. C. (1996). School effectiveness in East Asia: Concepts, origins and implications. Journal of Educational Administration, 34(5), 32-49.

Fei, H. T. (1985). Xiangtu zhongguo [Earthbound China]. Hong Kong: Joint Publishers. (Original work published 1947)

Gardner, H. (1984). The development of competence in culturally defined domains. In R. A. Shweder \& R. A. LeVine (Eds.), Culture theory: Essays on minds, selfand emotion (pp. 257-275). Cambridge, England: Cambridge University Press.

Gardner, H. (1989). To open minds: Chinese clues to the dilemma of contemporary education. New York: Basic Books.

Ho, D. Y. F. (1976). On the concept of face. American Journal of Sociology, 81, 867-884.

Hofstede, G. (1980). Culture's consequences: International differences in work-related values. Beverly Hills, CA: Sage.

Hofstede, G. (1991). Cultures and organisations: Software of mind. London: McGraw-Hill.

Hoy, W. K., \& Miskel, C. G. (1996). Educational administration: Theory, research, and practice (5th ed.). New York: McGraw-Hill.

Hsu, F. L. K. (1971). Psychosocial homeostasis and jen: Conceptual tools for advancing psychological anthropology. American Anthropologists, 73, 23-44.

Hsu, F. L. K. (1985). The self in cross-cultural perspectives. In A. J. Marsella, G. Devos, \& F. L. K. Hsu (Eds.), Culture and self: Asian and Western perspectives (pp. 24-55). New York: Tavistock.

Inkeles, A. (1997). Continuity and change in popular values on the Pacific Rim. In J. Montgomery (Ed.), Values in education: Social capital formation in Asia and the Pacific (pp. 71-91). Hollis, CA: Hollis Publishing Company/Soka University of America.

Kim, U., Triandis, H. C., Kagitchibasi, C., Choi, S. C., \& Yoon, G. (Eds.). (1994). Individualism and collectivism: Theory, methods, and applications. Thousand Oaks, CA: Sage.

Liu, C. L. (1990). Zhongguo xitong siwei: Wenhua jiyin toushi [The Chinese systems thinking: Perspectives on cultural genes]. Beijing: China Social Science Press.

Liu, T. Y. (1988). Address at the Congregation for Honorary Doctorate Degrees. University of Hong Kong Gazette, 35, 46-47.

Liu, Y. J. (Ed.). (1993). Book of major educational events in China. Hangzhou, China: Zhejiang Educational Press.

Lynn, R. (1988). Educational achievement in Japan: Lessons for the West. London: Macmillan.

McKay, W. F. (1992). Mother tongue, other tongues and link languages: What they mean in a changing word. Prospect, 22(1), 41-52.

Miyazaki, I. (1976). China's examination hell: The civil service examination in imperial China (C. Schirokauer, Trans.). New Haven, CT: Yale University Press. (Original work published 1963)

Redding, G. (1990). The spirit of Chinese capitalism. New York: deGruyter.

Schein, E. H. (1992). Organizational culture and leadership (2nd ed.). San Francisco: Jossey-Bass. 


\section{K. M. Cheng}

Schirokauer, C. (1976). Introduction. In I. Miyazaki (Ed.), China's examination hell: The civil service examination in imperial China (C. Schirokauer, Trans., pp. 7-10). New Haven, CT: Yale University Press. (Original work published 1963)

Stevenson, H. W., \& Lee, S. (1997). The East Asian version of whole-class teaching. In W. K. Cummings \& P. G. Altbach (Eds.), The challenge of Eastern Asian education: Implications for America (pp. 33-50). Albany: State University of New York Press.

Stevenson, H. W., \& Stigler, J. W. (1992). The learning gap: Why our schools are failing and what we can learn from Japanese and Chinese education. New York: Summit.

Tobin, J. J., Wu, D. Y. H., \& Davison, D. H. (1989). Preschool in three cultures: Japan, China and the United States. New Haven, CT: Yale University Press.

White, M. (1987). The Japanese educational challenge: A commitment to children. New York: Free Press. 
http://www.jstor.org

\section{LINKED CITATIONS \\ - Page 1 of 1 -}

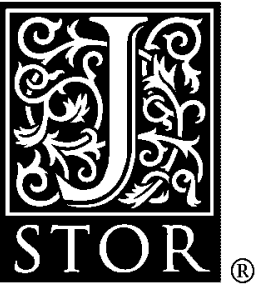

You have printed the following article:

\section{Can Education Values Be Borrowed? Looking into Cultural Differences}

Kai-ming Cheng

Peabody Journal of Education, Vol. 73, No. 2, Leading Schools in a Global Era: A Cultural Perspective. (1998), pp. 11-30.

Stable URL:

http:/links.jstor.org/sici?sici=0161-956X\%281998\%2973\%3A2\%3C11\%3ACEVBBL\%3E2.0.CO\%3B2-K

This article references the following linked citations. If you are trying to access articles from an off-campus location, you may be required to first logon via your library web site to access JSTOR. Please visit your library's website or contact a librarian to learn about options for remote access to JSTOR.

\section{References}

\section{On the Concept of Face}

David Yau-fai Ho

The American Journal of Sociology, Vol. 81, No. 4. (Jan., 1976), pp. 867-884.

Stable URL:

http://links.jstor.org/sici?sici=0002-9602\%28197601\%2981\%3A4\%3C867\%3AOTCOF\%3E2.0.CO\%3B2-3

\section{Psychosocial Homeostasis and Jen: Conceptual Tools for Advancing Psychological Anthropology}

Francis L. K. Hsu

American Anthropologist, New Series, Vol. 73, No. 1. (Feb., 1971), pp. 23-44.

Stable URL:

http://links.jstor.org/sici?sici=0002-7294\%28197102\%292\%3A73\%3A1\%3C23\%3APHAJCT\%3E2.0.CO\%3B2-J 